\title{
A long non-coding RNA HOTTIP expression is associated with disease progression and predicts outcome in small cell lung cancer patients
}

Yanqin Sun ${ }^{1,2+}$, Yuanyuan Zhou $^{3+}$, Yifeng Bai ${ }^{4+}$, Qiongyao Wang ${ }^{1}$, Jiarong Bao ${ }^{1}$, Yingshan Luo ${ }^{1}$, Ying Guo ${ }^{5^{*}}$ and Linlang Guo ${ }^{1 *}$

\begin{abstract}
Background: Despite progress in treatment of small cell lung cancer (SCLC), the biology of the tumor still remains poorly understood. Recently, we globally investigated the contributions of InCRNA in SCLC with a special focus on sponge regulatory network. Here we report IncRNA HOTTIP, which is specifically amplified in SCLC, is associated with SCLC proliferation and poor prognosis of patients.

Methods: RT-GPCR was used to investigate the expression of HOTTIP in SCLC tissues and cell lines. The role of HOTTIP in SCLC cell proliferation was demonstrated by CCK8 assay, colony formation assay, flow cytometry analysis and in vivo SCLC xenograft model in nude mice through HOTTIP loss- and gain-of-function effects. Western blot assay was used to evaluate gene expression in cell lines at protein level. RNA pull-down, Mass spectrometry and RNA binding protein immunoprecipitation (RIP) were performed to confirm the molecular mechanism of HOTTIP involved in SCLC progression.

Results: We found that HOTTIP was overexpressed in SCLC tissues, and its expression was correlated with the clinical stage and the shorter survival time of SCLC patients. Moreover, HOTTIP knockdown could impair cell proliferation, affect the cell cycle and inhibit tumor growth of mice, while HOTTIP overexpression might enhance cell proliferation and cell cycle in vitro and in vivo. Mechanistic investigations showed that HOTTIP functions as an oncogene in SCLC progression by sponging miR-574-5p and affecting the expression of polycomb group protein EZH1.

Conclusions: Overall, we identified that HOTTIP was involved in SCLC tumorigenesis through the ceRNA network "HOTTIP/miR-574-5p/EZH1". Our findings not only illuminate how HOTTIP confers an oncogenic function in SCLC pathogenesis, but also underscore a novel gene expression governing hallmarks in the disease.
\end{abstract}

Keywords: Small cell lung cancer (SCLC), Hottip, Proliferation

\footnotetext{
*Correspondence: guohanjing001@163.com; linlangg@yahoo.com

${ }^{\dagger}$ Equal contributors

${ }^{5}$ Department of Organ transplantation, Zhujiang Hospital, Southern Medical University, Guangzhou 510282, China

'Department of Pathology, Zhujiang Hospital, Southern Medical University,

Guangzhou 510282, China

Full list of author information is available at the end of the article
} 


\section{Background}

Small cell lung cancer (SCLC), which accounts for approximately $15 \%$ of lung cancer, is one of the most malignant diseases world-wide, with a high mortality [1]. Unlike most malignancies, the majority of patients suffering from SCLC are diagnosed at advanced stages accompany with early and distant metastasis [2]. Hence, an intensive research of molecular mechanism involved in SCLC pathogenesis is vital for the identification of diagnostic and therapeutic targets.

Non-coding RNAs account for more than $90 \%$ of the transcriptome without protein-coding potential. Therein, microRNAs (miRNAs, 19-25 nucleotides) have been extensively studied, thousands of which regulate up to $30 \%$ of their protein-encoding target genes [3]. Additionally, long non-coding RNAs (lncRNAs) with length over 200 nucleotides, have been identified to play crucial regulatory roles in tissue differentiation, proliferation, migration, invasion and apoptosis [4]. Recent studies have indicated that, lncRNA could regulate the expression of some key oncogenes or tumor suppressor genes and affect the occurrence and development of tumor through IncRNA-miRNA or IncRNAmRNA interaction. Competing endogenous RNA (ceRNA) was first proposed by Pandolfi PP et al. and had been proven as one of the important mechanisms in lncRNA regulation $[5,6]$. Therefore, several lncRNAs including HOTAIR, HOXA11-AS, MALAT1 and H19 have been confirmed as ceRNAs in tumorigenesis, lung cancer is included [7]. Despite identification of these lncRNAs, the prevalence and functional significance of lncRNA-mediated sponge regulation and their relevant targets in SCLC remain unclear.

The lncRNA HOTTIP (HOXA transcript at the distal tip), a newly identified IncRNA, located at the $5^{\prime}$ end of the HOXA cluster, which is a key locus control element of HOXA genes and distal identity, and is brought into close proximity to the 5' HOXA genes by chromosomal looping [8]. Existing studies have found that, large domains of HOX gene cluster are occupied by Polycomb Repressive Complex 2 (PRC2), which maintains the repressive histone marker H3K27me3 [9]. PRC2 is a sort of important gene expression regulatory elements, which mediates H3K27 methylation regulation and cause polycomb gene (PcG) silencing, then close down some tumor suppressor genes and cause tumorigenesis [10]. PRC2 is composed of several members including SUZ12, EZH1, EZH2 and EED. Among them, enhancer of zeste homolog 1 (EZH1) protein is an key methyltransfer enzyme in PRC2 components, which have RNA binding domains and may be combined with HOTAIR as well as other lncRNAs [11]. RIP-sequencing identified thousands of lncRNAs including HOTAIR, whose interaction with PRC2 are essential for their recruitment [12]. HOTTIP is also found to be associated with PRC2 and play a critical role in various malignancies including hepatocellular carcinoma, pancreatic cancer, gastric cancer, colorectal cancer and so on [13].
Until now, the prevalence and functional significance of lncRNA-mediated sponge regulation and their relevant targets in SCLC are unclear. Our previous study based on IncRNA array has shown that HOTTIP is upregulated in SCLC multidrug resistant cells (H69AR) compared to its parental H69 cell (data not shown). We further found that HOTTIP was not only related to SCLC chemo-resistance, but also closely associated with SCLC cell proliferation. In the present study, we attempt to investigate HOTTIP-mediated sponge regulatory network of protein-coding driver genes in SCLC pathogenesis. We also validate the tumor-promoting function of HOTTIP predicted to serve as miRNA sponge and positively regulate the expression of EZH1. Our study suggests an important role of HOTTIP in SCLC development and implied a therapeutical strategy of manipulating oncogene function through modulating HOTTIP-mediated sponge regulation.

\section{Results \\ HOTTIP is up-regulated in SCLC and associated with poor prognosis of SCLC patients}

Gene expression array analysis on H69 and H69AR cell lines showed 1443 differentially expressed lncRNAs statistically significant, their functions are involved in cell cycle gene regulation, apoptosis, enzyme activity regulation, metabolism, signal transduction activity and so on (Additional file 1: Fig. S1A-B). Among them, 20 HOX family members including lncRNA HOTTIP were up-regulated more than 10-fold changes in H69AR compared to $\mathrm{H} 69$ cell (Fig. 1a-b), which were validated in several SCLC cell lines by RT-qPCR (Fig. 1c). To further confirm these results, the level of HOTTIP expression was determined in SCLC clinical samples by RT-qPCR. Among them, 50 biopsy SCLC tissues and the control non-tumoral lung tissues were collected from patients before chemotherapy at Shunde Hospital of Southern Medical University. HOTTIP Expression was significantly up-regulated in SCLC tissues compared with non-tumoral lung tissues (Fig. 1d). Examination of the correlation between HOTTIP expression and clinical pathological features showed that HOTTIP was correlated with disease stage and median survival (Table 1). With regard to overall survival, patients with high HOTTIP expression had a significantly poorer prognosis than those with low HOTTIP expression (Fig. 1e). These results above imply a potential role of HOTTIP as a novel bio-marker for SCLC progression.

\section{Manipulation of HOTTIP levels in SCLC cell lines}

HOTTIP expression was examined in SCLC cell lines (H69, H446, H146, H446AR, H69AR) and the normal human bronchial epithelial cell lines (16-HBE) by RTqPCR. Among them, HOTTIP expression in H146 and 
a

\begin{tabular}{ll} 
GeneSymbol & Fold change \\
\cline { 2 - 2 } HOXD4 & 23.6123 \\
HOTTIP & 14.9108 \\
HOXA13 & 13.5580 \\
HOXD3 & 10.9270 \\
nc-HOXA11-90 & 4.1947 \\
nc-HOXA1-58 & 2.8622 \\
nc-HOXA4-65 & 2.8429 \\
HOXA6 & 2.7588 \\
nc-HOXA1-59 & 2.7242 \\
HOXA2 & 2.6193 \\
nc-HOXA1-55 & 2.55047 \\
nc-HOXA11-86 & 2.52422 \\
HOXA3 & 2.4684 \\
HOXA7 & 2.3776 \\
nC-HOXA13-100 & 2.3053 \\
nc-HOXA13-101 & 2.1993 \\
HOXA11 & 2.1919 \\
HOXA1 & 1.4976 \\
nc-HOXB9-184 & 1.4810 \\
HOXB6 & 0.3897 \\
\hline H69AR cell line/H69 cell line (scLC) (n=3) \\
\hline 2 & \\
\hline
\end{tabular}

d

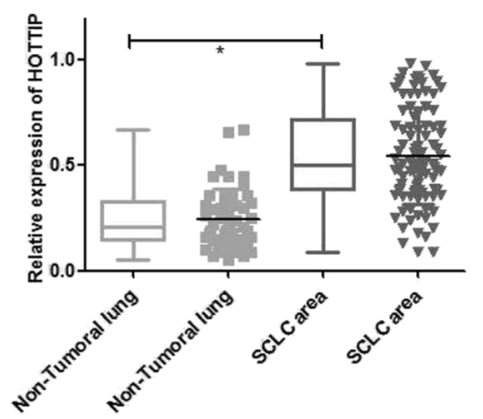

b
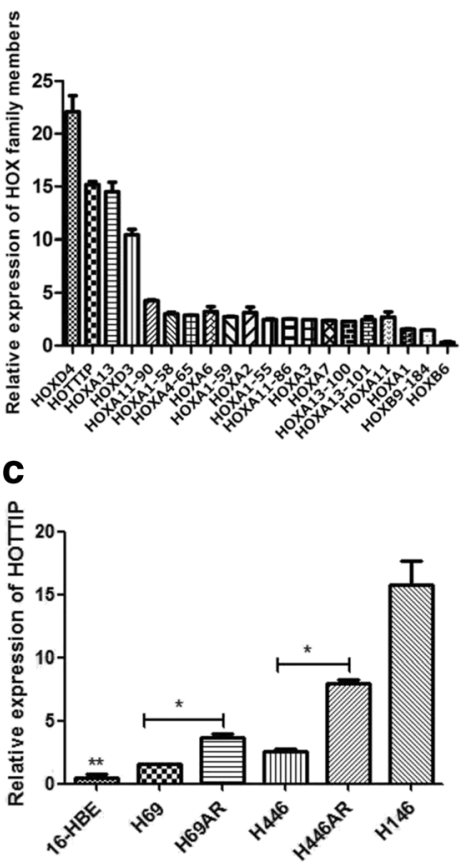

e

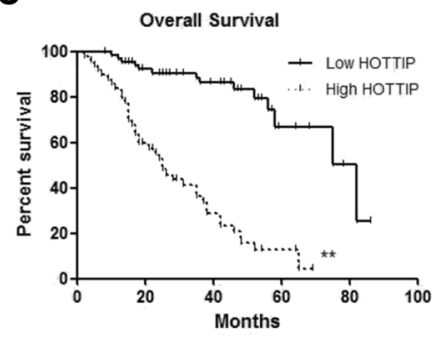

Fig. 1 Gene differential expression array analysis and confirmation in SCLC cell lines and FFPE tissues. a \& b Differentially expressed HOX genes were involved. c The level of HOTTIP expression in cell lines showed differential expression in 5 SCLC cell lines and the normal human bronchial epithelial cell line (16-HBE). $\mathbf{d}$ The level of HOTTIP expression in SCLC clinical tissues and the non-tumoral lung tissues. e Patients with high HOTTIP expression had a significantly poorer prognosis than those with low HOTTIP expression. ${ }^{*}, P<0.05$; **, $P<0.01$

H446AR are significantly higher than those in H69 and H446, respectively. Similarly, HOTTIP expression in either of the four SCLC cell lines is higher over 16-HBE cell (Fig. 1c). Hence, we used H146 and H446AR cells for loss-of-function experiments, while H69 and H446 cells were used for gain-of-function experiments. A pcDNA3.1-HOTTIP expression vector, HOTTIP siRNA sequences as well as the negative controls were transfected into H69/H446 and H146/H446AR cells, respectively, the effects of overexpression or interference were validated by RT-qPCR at $24 \mathrm{~h}$ after transfection (Fig. 2a-b).
HOTTIP regulates SCLC cell proliferation in vitro as well as the cell cycle

To comprehensively investigate the role of HOTTIP in SCLC progression, we additionally established stable HOTTIP knockdown H146 and H446AR cell lines by lentivirus infection (Additional file 1: Fig. S1C-D). CCK8 assays revealed that HOTTIP overexpression in $\mathrm{H} 69$ / H446 cells resulted in much increased cell proliferation and a high cell survival rate (Fig. 2c). However, knockdown of HOTTIP reduced cell proliferation compared with negative controls in both cell lines (Fig. 2d). To further investigate the growth inhibition observed following 
Table 1 Clinicopathological data of the SCLC studied cohort

\begin{tabular}{|c|c|c|c|c|}
\hline \multirow[t]{2}{*}{ Patients Characteristics } & \multicolumn{4}{|c|}{ HOTTIP expression } \\
\hline & - & + & $x^{2}$ & $P$ Value* \\
\hline All cases $(N=115)$ & 27 & 88 & & \\
\hline Age & & & 0.5957 & 0.4402 \\
\hline$\leq 56$ & 10 & 40 & & \\
\hline$>56$ & 17 & 48 & & \\
\hline Gender & & & 0.4183 & 0.5178 \\
\hline Male & 15 & 55 & & \\
\hline Female & 12 & 33 & & \\
\hline Disease stage & & & 9.6084 & 0.0019 \\
\hline Limited disease (LD) & 20 & 33 & & \\
\hline Extensive-stage disease (ED) & 7 & 50 & & \\
\hline Median Survival (5-36 months) & & & 23.5898 & $<0.001$ \\
\hline Survival & 19 & 18 & & \\
\hline Death & 8 & 70 & & \\
\hline
\end{tabular}

*For analysis of correlation between of HOTTIP levels and clinical features, Fisher's Exact Test were used. Results were considered statistically significant at $P<0.05$

HOTTIP knockdown, cell-cycle profiles of HOTTIP knockdown cells and negative controls were carried out using flow cytometry. Suppression of HOTTIP led to a decrease in the number of cells in the S-phase and an unstable cell number in the G2-phase (Fig. 2e-f, Additional file 2: Fig. S2D), while overexpression of HOTTIP resulted in an increase in the S-phase and a decrease in the G2-phase of cell number (Fig. 2g-h, Additional file 2: Fig. S2E).

Furthermore, plate colony forming assay and soft agar colony forming assay (for suspension-cultured H69 cell) were used to investigated the effect of HOTTIP on cell proliferation, HOTTIP overexpression increased the colony formation ability of $\mathrm{H} 446 / \mathrm{H} 69$ cells (Fig. 3a), while HOTTIP knockdown inhibited the colony formation ability of H446AR/H146 cells (Fig. 3b).

\section{HOTTIP regulates SCLC cell growth in vivo}

The effect of HOTTIP to confer SCLC biology was further examined using an in vivo SCLC xenograft model in nude mice. As shown in Fig. 3c and d, tumor growth was most significantly inhibited in mice following HOTTIP knockdown treatment either in H146 cell or in H446AR cell compared with the NC groups. After subcutaneous injection for 15 days, the mean tumor volume for the NC groups were more and more markedly larger than their HOTTIP knockdown treating groups, respectively (Fig. 3e). As expected, the tumor weight statistic of excised tumor showed a similar trend to that of tumor volume (Fig. 3f).

\section{HOTTIP may be involved in SCLC biology by a miRNA- IncRNA-mRNA regulatory network}

There were 81 miRNAs related closely to SCLC biology by miRNA microarray, among them 37 miRNAs expressed higher in H69 cell compared to H69AR cell, while 44 miRNAs expressed lower in H69 cell compared to H69AR cell (Additional file 1: Fig. S1E-F, Table 2). Using the bioinformatics website RNA22-seq (https:// cm.jefferson.edu/), 5 miRNAs including miR-574-5p were predicted that have targeted binding relationship with HOTTIP and have been testified by RT-qPCR (Additional file 1: Fig. S1G).

Our previous studies have demonstrated that EZH1, EZH2 and other polycomb group genes had been proved to be involved in the development of SCLC even the occurrence of drug resistance. We also found that EZH1 contains putative regions that matches to the seed sequence of miR-574-5p but not match other miRNAs by further searching in RNA22-seq database (Fig. 4a). Hence, miR-574-5p was selected for further experiments in our study (Additional file 2: Fig. S2A). Our results verified that miR-574-5p negatively regulated the expression of HOTTIP and EZH1 by RT-qPCR and Western blot (Additional file 2: Fig. S2B-C, Fig. 4b-c), and co-expression relationship analysis of miR-574-5p and HOTTIP in clinical tissues showed a negative correlation (Fig. 4d). Moreover, HOTTIP overexpression led to an increase of miR-574-5p expression (Fig. 4e), while HOTTIP knockdown led to EZH1 decreasing significantly (Fig. 4f), and co-expression relationship analysis of EZH1 and HOTTIP in clinical tissues showed a positive correlation (Fig. 4g). These results above suggest HOTTIP may be involved in a novel regulatory network of miRNA-574-5p-HOTTIP-EZH1.

In order to clarify the role of HOTTIP in the novel regulatory complex, we carried out the co-transfection dual luciferase reporter assay and found that, luciferase activity for HOTTIP and EZH1 were reduced respectively compared with the control when miR-574-5p expressed (Fig. 5a-b), and the inhibited reporter plasmid luciferase activity for EZH1 was reversed in the presence of HOTTIP (Fig. 5c), which indicates that HOTTIP acts as an endogenous "sponge" by binding miR-574-5p, thus abolishing the miRNA-574-5p induced repressing activity on the EZH1 3'-UTR.

As we all know, miRNAs are present in the form of miRNA ribonucleoprotein complex within the cytoplasm, there the core component of RISC (RNA-induced silencing complex), Ago2 is involved. To detect whether HOTTIP is present in miRNPs, RNA pull-down, mass spectrometry and Western blot experiments were carried out and found that HOTTIP may interact with Ago 2 protein directly (Fig. 5 d-e, Table 3 ). Moreover, RIP experiments showed that Ago2 had a function in the 

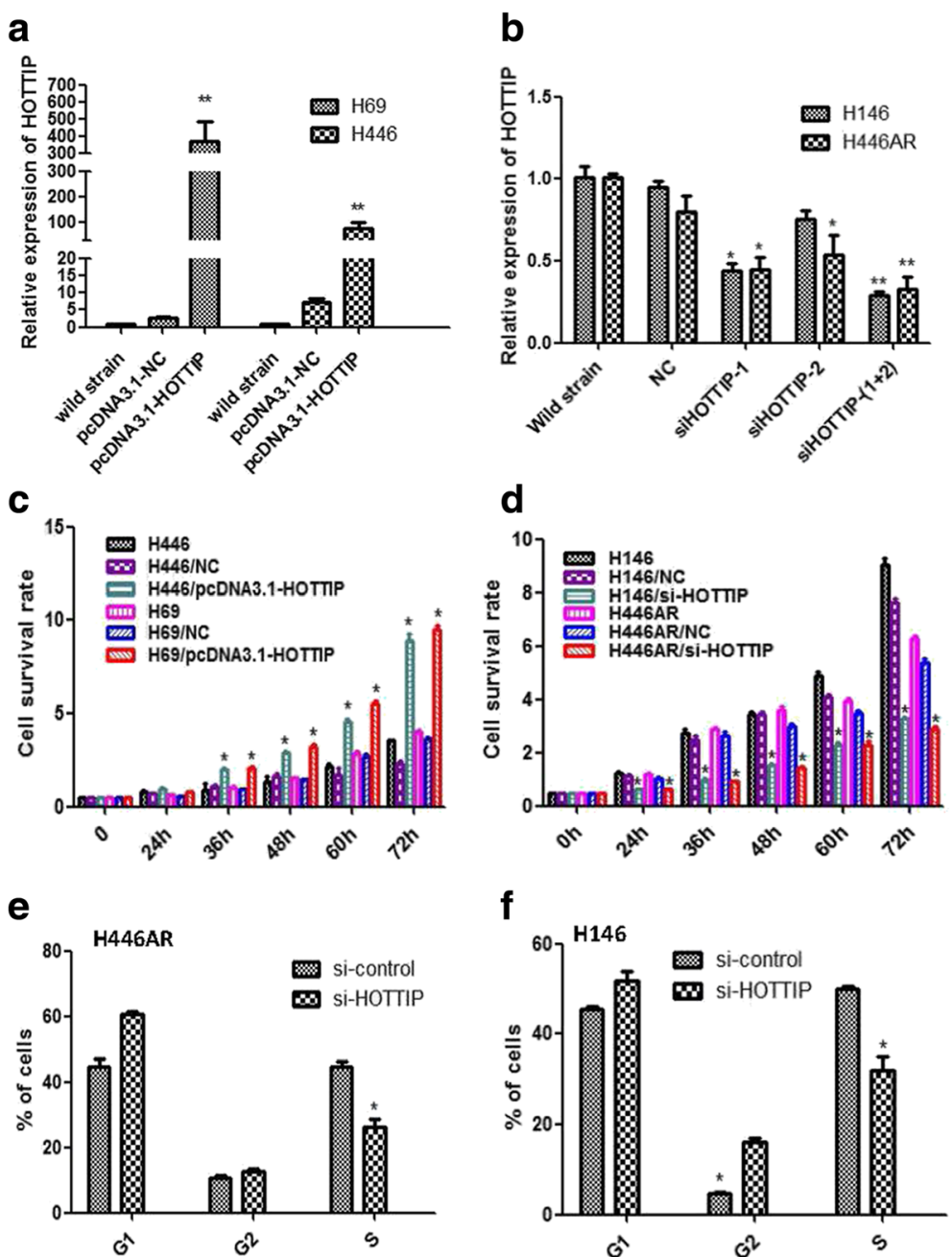

f
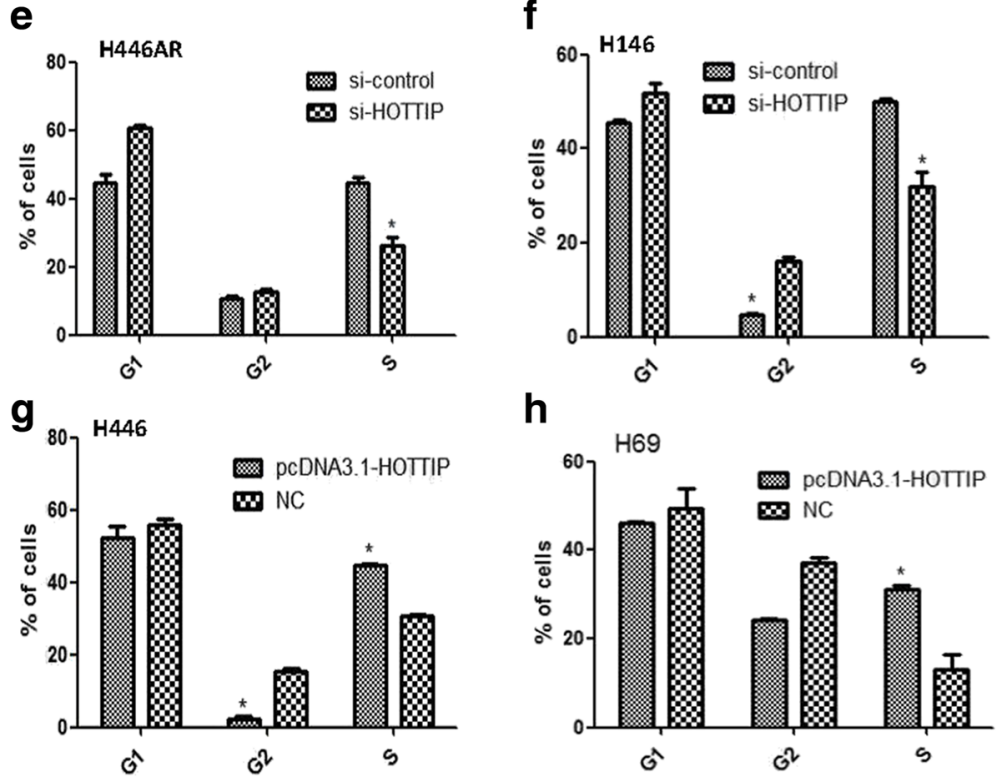

Fig. 2 HOTTIP may regulate SCLC cell proliferation and cell cycle. a A pCDNA3.1-HOTTIP expression vector was transfected successfully into H69 and $\mathrm{H} 446$ cells, respectively. b HOTTIP RNAi sequences were transfected into H146 and H446AR cells, respectively. c CCK8 assay was used to detect the effect of HOTTIP on SCLC cell proliferation after HOTTIP overexpression. $\mathbf{d}$ CCK8 assay was used to detect the effect of HOTTIP on SCLC cell proliferation after HOTTIP knockdown. e \& $\mathbf{f}$ Flow-cytometric analysis was used for cell cycle detection after HOTTIP knockdown in H446AR and H146 cells. $\mathbf{g}$ \& h Flow-cytometric analysis was used for cell cycle detection after HOTTIP overexpression in H446 and H69 cells. * $P<0.05 ;{ }^{* *}, P<0.01$

formation of HOTTIP and miR574-5p complex and in their regulation of EZH1 (Fig. 5f), Which suggests HOTTIP, miR-574-5p and Ago2 combination formed the RNA silencing complex, and further clarify the direct interaction of miR-574-5p, HOTTIP and EZH1. These data above indicate that HOTTIP may modulate EZH1 expression as a ceRNA once more.

It is necessary to add that, to better understand the relationship between HOTTIP and miR-574-5p and EZH1, we have evaluated cellular localization of 

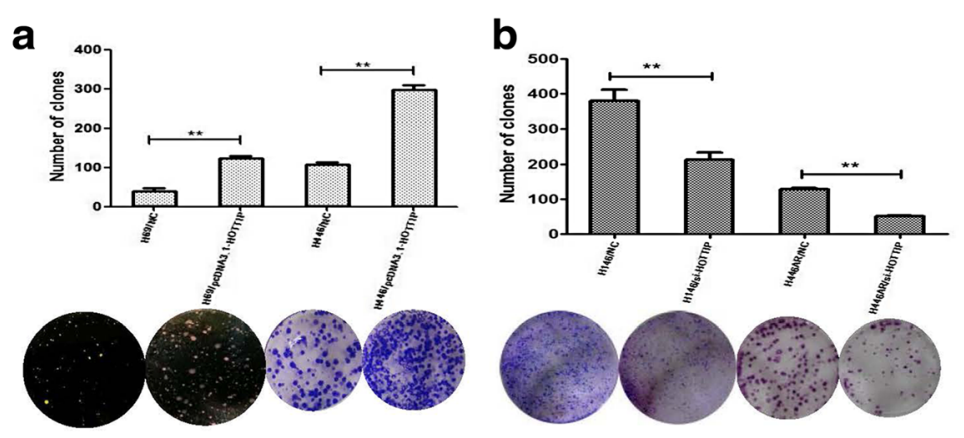

C
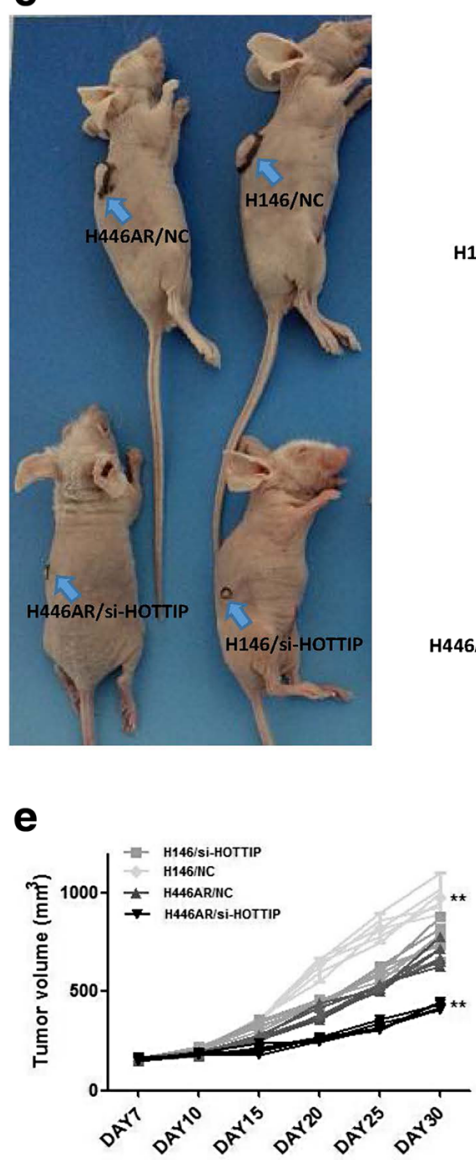

d
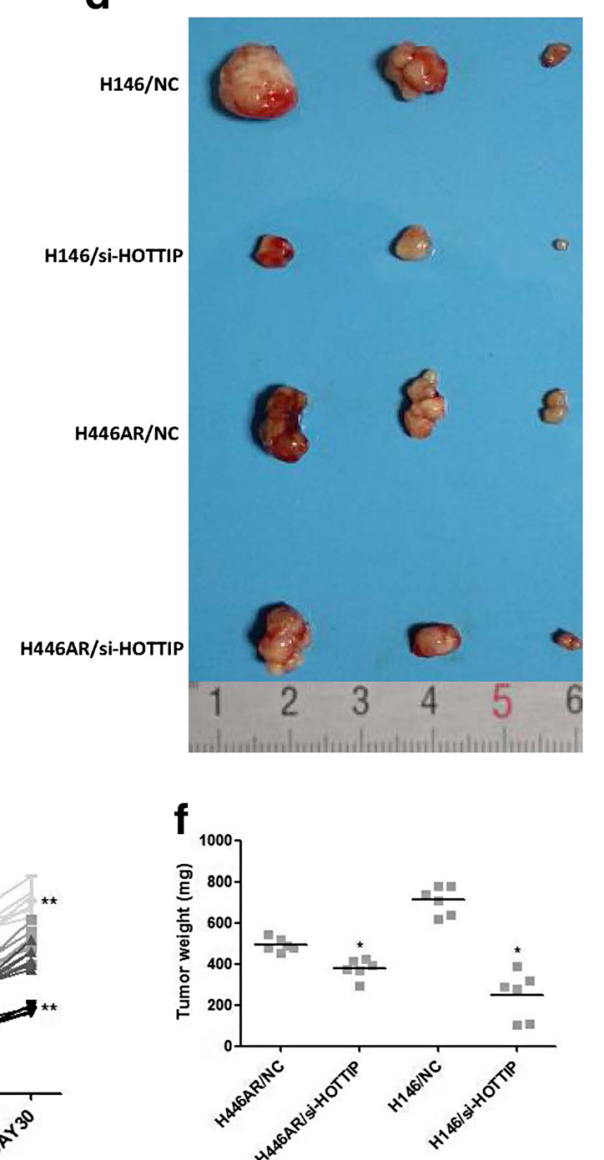

Fig. 3 HOTTIP may regulate SCLC cell proliferation in vitro and xerograft tumor growth of in vivo. a Plate and soft agar colony formation assay was used to detect the effect of HOTTIP overexpression on SCLC cell proliferation in vitro. $\mathbf{b}$ Plate colony formation assay were used to detect the effect of HOTTIP knockdown on SCLC cell proliferation in vitro. c Images of nude mice with xerograft tumor in each group. $\mathbf{d}$ Excised tumors' image from nude mice in each group. e Volume change curve of each group measured on the indicated days. $\mathbf{f}$ Tumor weights of each group were determined. ${ }^{*}, P<0.05 ;{ }^{*}, P<0.01$

HOTTIP in SCLC cells (Additional file 3: Fig. S3A). RNA was extracted from both nuclear and cytoplasmic fractions of cells separately, then HOTTIP was detected predominantly in the nuclear fraction as U6 RNA did in SCLC cells. Considering the exclusive localization of HOTTIP in the nuclei and Ago2 generally interacts with RNAs exported to cytoplasm, we examined if expression of 'nuclear' HOTTIP and EZH1 could be inhibited by miRNA-574-5p via RT-qPCR using nuclear and cytoplasmic RNAs isolated from cells treated with miR-574-5p. As shown in Additional file 3: Fig. S3B-E, we found that miRNA-574-5p could directly silence the expression of HOTTIP and EZH1 in either the nucleus or cytoplasm. 
Table 2 Differentially expressed miRNAs in H69/H69AR cells

\begin{tabular}{|c|c|c|c|c|}
\hline \multirow[t]{2}{*}{ No. } & \multirow[t]{2}{*}{ Probe_ID } & \multirow{2}{*}{$\begin{array}{l}\text { H69-су3 } \\
\text { Signal }\end{array}$} & H69AR-cy3 & $\log 2(\mathrm{H} 69 \mathrm{AR} / \mathrm{H} 69)$ \\
\hline & & & \multicolumn{2}{|l|}{ Signal } \\
\hline 1 & hsa-miR-375 & 6454.34 & 20.05 & -8.31 \\
\hline 2 & hsa-miR-200b & 6273.58 & 23.22 & -8.19 \\
\hline 3 & hsa-miR-335* & 3835.09 & 13.18 & -8.07 \\
\hline 4 & hsa-miR-335 & 3663.11 & 13.79 & -8.04 \\
\hline 5 & hsa-miR-224 & 4.35 & 866.73 & 7.70 \\
\hline 6 & hsa-miR-143 & 4.36 & 789.54 & 7.41 \\
\hline 7 & hsa-miR-216b & 1367.48 & 7.65 & -7.41 \\
\hline 8 & hsa-miR-145 & 6.14 & 890.69 & 7.06 \\
\hline 9 & hsa-miR-100 & 43.57 & 4656.66 & 6.64 \\
\hline 10 & hsa-miR-200c & $17,307.45$ & 278.54 & -5.94 \\
\hline 11 & hsa-miR-217 & 448.40 & 6.73 & -5.89 \\
\hline 12 & hsa-miR-493* & 468.53 & 9.02 & -5.75 \\
\hline 13 & hsa-miR-7 & 8780.53 & 174.39 & -5.65 \\
\hline 14 & hsa-miR-432 & 2116.51 & 42.31 & -5.65 \\
\hline 15 & hsa-miR-199a-3p & 163.81 & 7822.89 & 5.61 \\
\hline 16 & hsa-miR-216a & 305.13 & 7.61 & -5.33 \\
\hline 17 & hsa-miR-487b & 593.66 & 15.51 & -5.26 \\
\hline 18 & hsa-miR-379* & 87.59 & 2.99 & -5.22 \\
\hline 19 & hsa-miR-99a & 31.32 & 1161.16 & 5.21 \\
\hline 20 & hsa-miR-199a-5p & 13.08 & 482.45 & 5.08 \\
\hline 21 & hsa-miR-214 & 273.73 & 9411.86 & 5.02 \\
\hline 22 & hsa-miR-382 & 525.03 & 19.72 & -4.86 \\
\hline 23 & hsa-miR-195 & 29.20 & 774.93 & 4.78 \\
\hline 24 & hsa-miR-379 & 421.69 & 16.33 & -4.70 \\
\hline 25 & hsa-miR-376a & 154.50 & 6.80 & -4.66 \\
\hline 26 & hsa-miR-31 & 19.84 & 453.26 & 4.64 \\
\hline 27 & hsa-miR-10a & 166.79 & 7.61 & -4.54 \\
\hline 28 & hsa-miR-495 & 432.48 & 19.53 & -4.51 \\
\hline 29 & hsa-miR-125b & 817.38 & $17,867.52$ & 4.44 \\
\hline 30 & hsa-miR-10b & 239.12 & 12.19 & -4.34 \\
\hline 31 & hsa-miR-376c & 152.76 & 8.74 & -4.26 \\
\hline 32 & hsa-miR-127-3p & 264.57 & 14.57 & -4.21 \\
\hline 33 & hsa-miR-485-3p & 201.48 & 11.46 & -4.15 \\
\hline 34 & hsa-miR-134 & 253.52 & 16.61 & -3.93 \\
\hline 35 & hsa-miR-654-3p & 135.44 & 9.21 & -3.89 \\
\hline 36 & hsa-miR-494 & 340.42 & 23.21 & -3.88 \\
\hline 37 & hsa-miR-299-5p & 63.59 & 4.52 & -3.81 \\
\hline 38 & hsa-miR-346 & 142.45 & 11.14 & -3.67 \\
\hline 39 & hsa-miR-483-5p & 732.65 & 54.49 & -3.63 \\
\hline 40 & hsa-miR-92b* & 8.74 & 83.51 & 3.35 \\
\hline 41 & hsa-miR-1224-5p & 242.56 & 26.22 & -3.33 \\
\hline 42 & hsa-miR-218 & 206.82 & 18.48 & -3.24 \\
\hline 43 & hsa-miR-708 & 9669 & 1088 & -312 \\
\hline
\end{tabular}

Table 2 Differentially expressed miRNAs in H69/H69AR cells (Continued)

\begin{tabular}{|c|c|c|c|c|}
\hline \multirow[t]{2}{*}{ No. } & \multirow[t]{2}{*}{ Probe_ID } & \multirow{2}{*}{$\begin{array}{l}\text { H69-су3 } \\
\text { Signal }\end{array}$} & \multirow{2}{*}{$\begin{array}{l}\text { H69AR-cy3 } \\
\text { Signal }\end{array}$} & \multirow[t]{2}{*}{$\log 2(\mathrm{H} 69 \mathrm{AR} / \mathrm{H} 69)$} \\
\hline & & & & \\
\hline 44 & hsa-miR-411* & 133.62 & 16.40 & -3.11 \\
\hline 45 & hsa-miR-301a & 19.88 & 178.36 & 3.06 \\
\hline 46 & hsa-miR-329 & 80.60 & 9.30 & -3.05 \\
\hline 47 & hsa-miR-26b & 333.25 & 2757.24 & 3.02 \\
\hline 48 & hsa-miR-486-5p & 20.88 & 168.02 & 2.98 \\
\hline 49 & hsa-miR-923 & 3989.25 & 569.35 & -2.84 \\
\hline 50 & hsa-miR-28-5p & 19.80 & 144.71 & 2.81 \\
\hline 51 & hsa-miR-149* & 428.72 & 74.95 & -2.75 \\
\hline 52 & hsa-miR-505* & 57.46 & 362.36 & 2.69 \\
\hline 53 & hsa-miR-485-5p & 76.11 & 12.85 & -2.68 \\
\hline 54 & hsa-miR-936 & 112.94 & 19.39 & -2.62 \\
\hline 55 & hsa-miR-29a & 78.94 & 460.97 & 2.61 \\
\hline 56 & hsa-miR-409-3p & 69.31 & 11.71 & -2.58 \\
\hline 57 & hsa-miR-1469 & 349.41 & 58.58 & -2.57 \\
\hline 58 & hsa-miR-24 & 879.82 & 4759.30 & 2.45 \\
\hline 59 & hsa-miR-765 & 92.39 & 19.76 & -2.44 \\
\hline 60 & hsa-miR-197 & 99.74 & 495.21 & 2.39 \\
\hline 61 & hsa-miR-99b & 489.09 & 2103.62 & 2.11 \\
\hline 62 & hsa-miR-125a-5p & 2121.30 & 9360.49 & 2.10 \\
\hline 63 & hsa-miR-23a & 3198.24 & $13,081.13$ & 2.02 \\
\hline 64 & hsa-miR-638 & 2752.88 & 699.84 & -1.98 \\
\hline 65 & hsa-miR-1275 & 2714.17 & 677.40 & -1.97 \\
\hline 66 & hsa-miR-27a & 515.20 & 2034.19 & 1.96 \\
\hline 67 & hsa-miR-21 & 7236.65 & $26,700.40$ & 1.84 \\
\hline
\end{tabular}

$\begin{array}{lllll}\mathbf{6 8} & \text { hsa-miR-574-5p } & \mathbf{2 9 7 . 3 9} & \mathbf{9 1 . 8 4} & \mathbf{- 1 . 7 0} \\ 69 & \text { hsa-miR-324-5p } & 40.85 & 131.84 & 1.69 \\ 70 & \text { hsa-miR-663 } & 341.14 & 128.67 & -1.53 \\ 71 & \text { hsa-miR-222 } & 583.09 & 1544.61 & 1.39 \\ 72 & \text { hsa-miR-421 } & 156.91 & 367.95 & 1.32 \\ 73 & \text { hsa-miR-221 } & 344.44 & 801.06 & 1.26 \\ 74 & \text { hsa-miR-27b } & 1254.00 & 2937.56 & 1.21 \\ 75 & \text { hsa-miR-23b } & 5303.07 & 12,176.63 & 1.20 \\ 76 & \text { hsa-miR-361-5p } & 2821.27 & 1247.87 & -1.18 \\ 77 & \text { hsa-miR-877 } & 352.14 & 789.34 & 1.17 \\ 78 & \text { hsa-miR-183 } & 1885.45 & 4147.32 & 1.16 \\ 79 & \text { hsa-miR-1246 } & 18,178.79 & 8399.43 & -1.11 \\ 80 & \text { hsa-miR-191 } & 4246.30 & 1992.85 & -1.09 \\ 81 & \text { hsa-miR-128 } & 490.61 & 1071.81 & 1.09 \\ 82 & \text { hsa-miR-130b } & 301.35 & 609.02 & 1.08 \\ 83 & \text { hsa-miR-1180 } & 124.32 & 260.40 & 1.07 \\ 84 & \text { hsa-miR-15a } & 321.22 & 667.43 & 1.03 \\ 85 & \text { hsa-miR-92a } & 27,966.93 & 14,178.41 & -1.00\end{array}$


Table 2 Differentially expressed miRNAs in H69/H69AR cells (Continued)

\begin{tabular}{|c|c|c|c|c|}
\hline \multirow[t]{2}{*}{ No. } & \multirow[t]{2}{*}{ Probe_ID } & \multirow{2}{*}{$\begin{array}{l}\text { H69-су3 } \\
\text { Signal }\end{array}$} & \multirow{2}{*}{$\begin{array}{l}\text { H69AR-cy3 } \\
\text { Signal }\end{array}$} & \multirow[t]{2}{*}{$\log 2($ H69AR/H69) } \\
\hline & & & & \\
\hline 86 & hsa-miR-132 & 270.45 & 533.41 & 0.98 \\
\hline 87 & hsa-miR-20b & 4633.50 & 2432.38 & -0.95 \\
\hline 88 & hsa-miR-92b & $16,350.76$ & 8266.02 & -0.94 \\
\hline 89 & hsa-miR-374b & 1210.23 & 617.94 & -0.93 \\
\hline 90 & hsa-miR-25 & 9060.44 & 4780.17 & -0.92 \\
\hline 91 & hsa-let-7b & $21,882.23$ & $11,552.59$ & -0.91 \\
\hline 92 & hsa-let-7e & $25,328.08$ & $13,470.29$ & -0.91 \\
\hline 93 & hsa-miR-1308 & $11,466.81$ & 6247.69 & -0.88 \\
\hline 94 & hsa-miR-425 & 475.65 & 272.28 & -0.80 \\
\hline 95 & hsa-let-7i & 8834.50 & $15,112.88$ & 0.78 \\
\hline 96 & hsa-miR-106b & 1731.98 & 2891.30 & 0.77 \\
\hline 97 & hsa-let-7c & $33,806.02$ & $20,255.98$ & -0.75 \\
\hline 98 & hsa-let-7d & $31,363.77$ & $18,654.38$ & -0.75 \\
\hline 99 & hsa-miR-20a & $10,936.77$ & 6714.28 & -0.68 \\
\hline 100 & hsa-miR-196a & 2828.72 & 1772.16 & -0.66 \\
\hline 101 & hsa-let-7f & $32,482.40$ & $20,436.54$ & -0.66 \\
\hline 102 & hsa-miR-342-3p & 932.23 & 1390.13 & 0.63 \\
\hline 103 & hsa-miR-106a & 8445.28 & 5478.16 & -0.61 \\
\hline 104 & hsa-miR-720 & 482.17 & 732.43 & 0.60 \\
\hline 105 & hsa-miR-17 & 8763.89 & 5901.69 & -0.59 \\
\hline 106 & hsa-miR-181a & 1184.53 & 1782.06 & 0.59 \\
\hline 107 & hsa-miR-30b & 1281.88 & 871.32 & -0.55 \\
\hline 108 & hsa-miR-19b & 1272.50 & 872.70 & -0.54 \\
\hline 109 & hsa-let-7a & $38,956.19$ & $26,905.20$ & -0.52 \\
\hline 110 & hsa-miR-9 & $30,484.05$ & $21,325.89$ & -0.52 \\
\hline 111 & hsa-let-7 g & 5184.47 & 7483.50 & 0.51 \\
\hline 112 & hsa-miR-182 & 5809.37 & 8192.36 & 0.50 \\
\hline 113 & hsa-miR-423-5p & 2331.59 & 3046.24 & 0.41 \\
\hline 114 & hsa-miR-1280 & 3304.08 & 4351.07 & 0.39 \\
\hline 115 & hsa-miR-93 & 2208.94 & 2880.50 & 0.39 \\
\hline 116 & hsa-miR-107 & 1519.29 & 1981.72 & 0.39 \\
\hline 117 & hsa-miR-16 & 8048.11 & $10,336.45$ & 0.34 \\
\hline 118 & hsa-miR-320c & 5008.38 & 3991.64 & -0.32 \\
\hline 119 & hsa-miR-320b & 4280.06 & 3403.00 & -0.29 \\
\hline 120 & hsa-miR-320a & 4926.46 & 3890.68 & -0.29 \\
\hline 121 & hsa-miR-9* & 7778.13 & 6630.25 & -0.25 \\
\hline 122 & hsa-miR-1826 & $16,122.78$ & $13,561.89$ & -0.24 \\
\hline
\end{tabular}

HOTTIP may be involved in SCLC biology partly by positively regulating $\mathrm{EZH} 1$

Further investigation showed a high expression of EZH1 in SCLC cell lines and clinical samples (Fig. 6a-b). Moreover, using immunohistochemistry technique, we confirmed the positively regulatory relationship between HOTTIP and EZH1 protein in the mice xenografts in vivo (Fig. 6c). Therefore, HOTTIP may be involved in SCLC pathogenesis by regulating EZH1.

\section{miR-574-5p may mediate the effect of HOTTIP on SCLC biology}

In the above section, we have proved the negative relevance between miR-574-5p and HOTTIP, but whether miR-574-5p is involved in SCLC biology is still unclear. By flow cytometry, cell-cycle profiles following miR-574$5 \mathrm{p}$ knockdown showed that suppression of miR-574-5p led to an increase in the number of cells in the S-phase and the G2-phase (Fig. 7a), which indicated that miR574-5p suppression led to an opposite effect on SCLC cell cycle with HOTTIP knockdown. Plate colony formation experiments showed that miR-574-5p knockdown may promote SCLC cell growth while miR-574-5p overexpression may inhibit that (Fig. 7b). Using CCK8 assay, we found that miR-574-5p knockdown may promote SCLC cell growth while miR-574-5p overexpression may inhibit that (Fig. 7c).

Therefore, HOTTIP, miR-574-5p, EZH1 were all involved in the pathogenesis of SCLC according to the results above. As a vital role, HOTTIP may be involved in SCLC through the regulatory network "HOTTIP/ miR-574-5p/EZH1".

\section{Discussion}

Recent studies have shown that dysregulated expression of lncRNAs in solid cancers reflects disease progression and may independently predict disease outcome $[14,15]$. HOTTIP, which lies at the $5^{\prime}$ tip of the HOXA locus and drives H3K27me3 and gene transcription by binding with WDR/MLL complex [8], has been identified as a critical factor with tumor progression and drug resistance in pancreatic cancer and lung cancer without SCLC [16]. In addition, HOTTIP has been identified as a negative prognostic factor in hepatocellular carcinoma patients [17]. In the present study, we demonstrate that HOTTIP is associated with SCLC tumor progression and disease outcome.

This present study provides the first insight into the effect of HOTTIP on SCLC cell behavior. Our results demonstrate a pivotal role of HOTTIP in SCLC pathogenesis and prognosis by applying gain- and loss-offunction experiments in vitro and in vivo. Firstly, by detecting the expression of HOTTIP in 50 cases of human SCLC biopsy tissues, we found that HOTTIP was up-regulated in SCLC tissues in comparison with non-tumoral lung tissues. Further investigation in SCLC tissues showed that HOTTIP up-regulation was correlated with advanced disease stage and shorter median survival time. Therefore, our data suggests that HOTTIP 
a

Wt 3'UTR 5...ACACC...CGC..GTGCAC...CCC..GC..CATA..GCATTTA 3'HOTTIP

TGAGT...GTG...TGAGTG..GTG..TG..GTGT..AGTGTGT 5'has-miR-574-5p

Wt 3'UTR 5 uaugggaCAUGCACACACACUCa 3'EZH1

3' uaugggaGUGUGUGUGUGUGAGu 5 'has-miR-574-5p

b

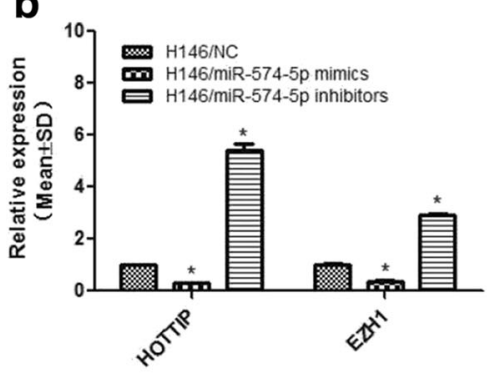

d

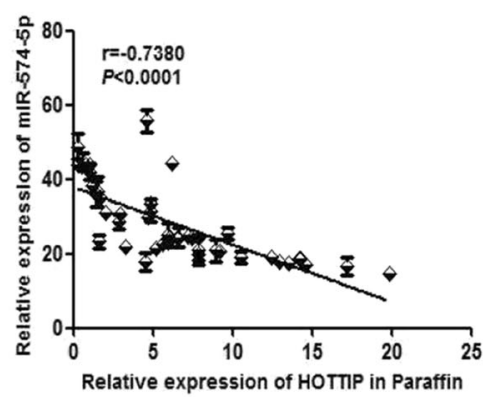

f

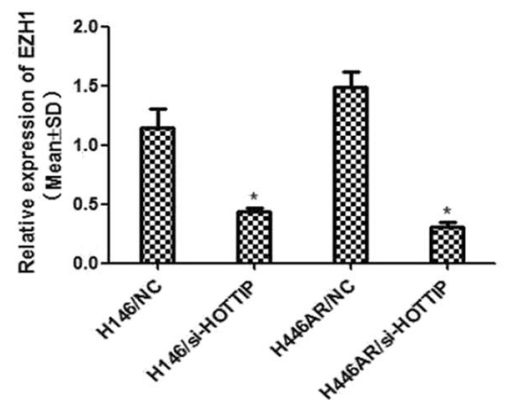

C

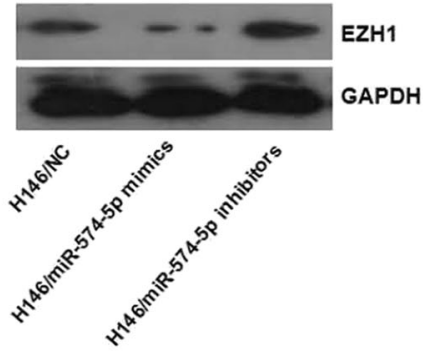

e

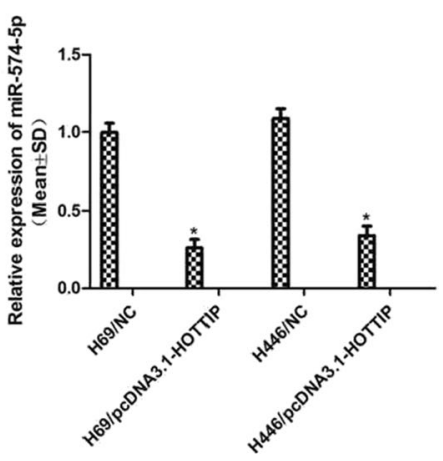

g

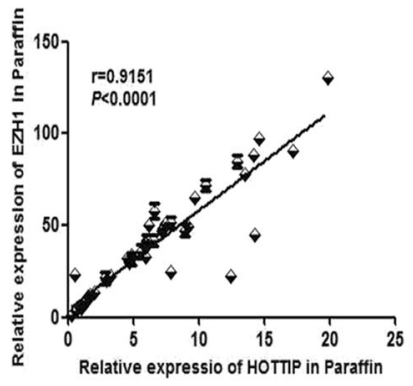

Fig. 4 HOTTIP may enhance EZH1 expression by sponging miR-574-5p. a Putative binding site of miR-574-5p in HOTTIP and EZH1 3'-UTR and the site of target mutagenesis we indicated. $\mathbf{b}$ miR-574-5p may negatively regulated expression of HOTTIP and EZH1 at mRNA level in H146 cell. $\mathbf{c}$ miR-574-5p may negatively regulated expression of EZH1 at protein level in $\mathrm{H} 146$ cell. $\mathbf{d}$ \& $\mathbf{g}$ Correlation analysis in SCLC tissues showed that HOTTIP expression is negatively associated with miR-574-5p but positively associated with EZH1 expression. e \& $\mathbf{f} H O T T I P$ may positively regulated EZH1 expression but negatively regulated miR-574-5p. ${ }^{*}, P<0.05$

is a novel independent prognostic factor for SCLC patients. Secondly, to explore the role of HOTTIP in SCLC biology, we carried out in vitro and in vivo experiments and found that HOTTIP overexpression promoted SCLC cell proliferation and colony formation while HOTTIP knockdown resulted in cell cycle arrest in G2 and S-phase, inhibited cell viability, colony formation in vitro and xenograft tumor growth in vivo. Hence, those findings above suggest HOTTIP may play a direct role in the modulation of multiple oncogenic properties and SCLC progression. Thirdly, further mechanistic investigations showed that HOTTIP might function as a role of ceRNA by binding miR-574-5p and abrogating their tumor suppressive function in this 

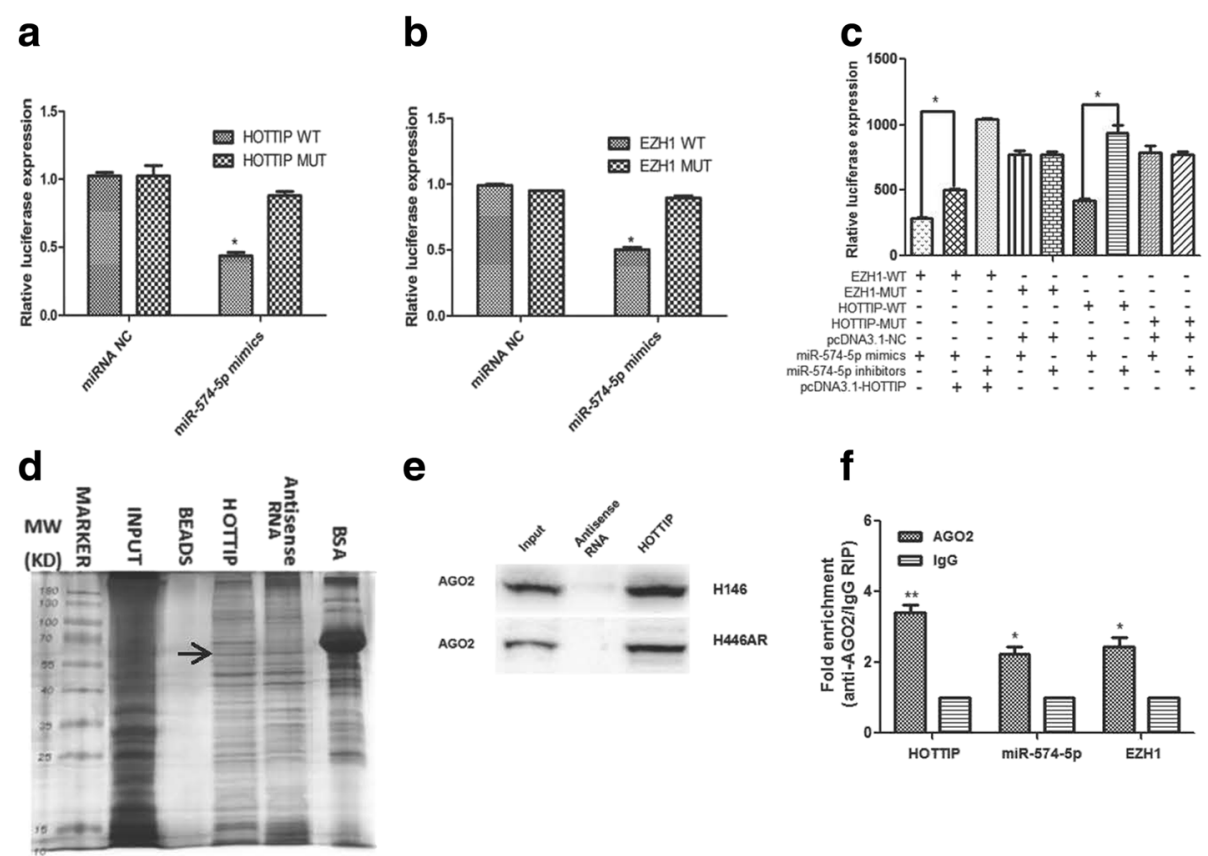

Fig. 5 Further experiments confirmed the ceRNA role of HOTTIP. a \& $\mathbf{b} \& \mathbf{c}$ Co-transfection dual luciferase reporter assay was used to demonstrate the ceRNA role of HOTTIP. $\mathbf{d} \& \mathbf{e}$ RNA pull-down and SDS-page assay showed HOTTIP may interact with Ago2 protein. $\mathbf{f}$ RIP experiments showed that Ago2 had a function in the formation of HOTTIP and miR574-5p complex and in their regulation of EZH1. ${ }^{*}, P<0.05 ;{ }^{* *}, P<0.01$

setting. Meanwhile, HOTTIP was involved in SCLC pathogenesis by up-regulating the expression of miRNA574-5p's target gene, EZH1, through competitively "sponging" this miRNA. Consequently, using a series of in vitro and in vivo experiments, our study suggested that HOTTIP is involved in SCLC tumorigenesis through the ceRNA network "HOTTIP/miR-574-5p/ EZH1".

In addition, we found that the HOTTIP knockdown could inhibit the expression of EZH1 protein in the mouse xenograft tissues except for its antagonistic effect on tumor growth, which also confirmed that the mechanism of HOTTIP involved in SCLC development possibly through positively regulating EZH1. Combining the above discussion, regulation of EZH1 expression by HOTTIP may be completed through the ceRNA mechanism, while comprehensive regulatory mechanism is still needed for further study.

In this study, dual luciferase reporter assay was used to confirm the existence of specific crosstalk between HOTTIP and EZH1 mRNA through competition for combining with miR-574-5p respectively. Furthermore, we used RNA pull-down, mass spectrometry and RIP assays to support the ceRNA mechanism of miR-574-5p and its target genes through modulating RISC. In addition, RT-qPCR assay revealed that EZH1 was mainly up-regulated in advanced stage SCLC tissues and associated with high HOTTIP expression. Altogether, the positive correlation between HOTTIP and EZH1 expression, and their relevance to miR-574-5p expression confirm our hypothesis that ceRNA may sequester miRNA, thereby protecting their target mRNAs from repression.

Although Ago2 commonly locates in cytoplasm, and mature miRNAs can be transported from cytoplasm to nucleus by importin $8[18,19]$. Hence, there is essential machinery for RISC working in nucleus, which explains why HOTTIP mainly exists in the nuclei but could physically interact with Ago2. Similar regulation mechanisms of miRNAs were also observed in other nucleus lncRNAs [20-22].

Future work will validate HOTTIP as a predictive biomarker for SCLC chemo-resistance, invasion and metastasis. A deeper characterization of the function and downstream signaling pathways influenced by HOTTIP deregulation is being investigated in our team, which may provide novel insights into the mechanisms of SCLC pathogenesis and possibly leading to the development of new therapeutic agents.

\section{Conclusions}

Taken together, our study showed that HOTTIP was highly expressed in SCLC tissues, which was closely associated with clinical stage and overall survival in SCLC 
Table 3 Mass spectrometry results of the proteins pulled down by HOTTIP

\begin{tabular}{|c|c|c|c|c|c|c|}
\hline Hits & Protein Name & Score & Mass & Matches & Sequences & emPAl \\
\hline 1 & UBE2N_HUMAN & 71 & 17,184 & $4(2)$ & $4(2)$ & 0.43 \\
\hline 2 & 4F2_HUMAN & 70 & 68,180 & $3(1)$ & $3(1)$ & 0.05 \\
\hline 3 & PGRC2_HUMAN & 70 & 23,861 & $4(2)$ & $4(2)$ & 0.3 \\
\hline 4 & TCAL4_HUMAN & 69 & 24,746 & $4(2)$ & $4(2)$ & 0.29 \\
\hline 5 & TM109_HUMAN & 69 & 26,194 & $5(3)$ & $4(3)$ & 0.43 \\
\hline 6 & ACBP_HUMAN & 68 & 10,038 & $3(2)$ & $3(2)$ & 0.82 \\
\hline 7 & CH60_HUMAN & 68 & 61,187 & $7(2)$ & $7(2)$ & 0.11 \\
\hline 8 & RA1L2_HUMAN & 67 & 34,375 & $7(1)$ & $5(1)$ & 0.1 \\
\hline 9 & RL29_HUMAN & 67 & 17,798 & $3(1)$ & $3(1)$ & 0.19 \\
\hline 10 & PPIA_HUMAN & 67 & 18,229 & $4(2)$ & $2(2)$ & 0.41 \\
\hline 11 & ZFP91_HUMAN & 66 & 64,261 & $2(1)$ & $2(1)$ & 0.05 \\
\hline 12 & SC61B_HUMAN & 66 & 10,025 & $1(1)$ & $1(1)$ & 0.35 \\
\hline 13 & LASP1_HUMAN & 66 & 30,097 & $3(2)$ & $3(2)$ & 0.23 \\
\hline 14 & T22D1_HUMAN & 65 & 109,649 & $4(2)$ & $4(2)$ & 0.06 \\
\hline 15 & WBP4_HUMAN & 65 & 42,652 & $9(1)$ & $5(1)$ & 0.08 \\
\hline 16 & ECE1_HUMAN & 65 & 87,906 & $5(2)$ & $5(2)$ & 0.08 \\
\hline 17 & ROA2_HUMAN & 64 & 37,464 & $6(2)$ & $6(2)$ & 0.18 \\
\hline 18 & RS28_HUMAN & 64 & 7893 & $1(1)$ & $1(1)$ & 0.45 \\
\hline 19 & BL1S2_HUMAN & 64 & 16,008 & $3(1)$ & $3(1)$ & 0.21 \\
\hline 20 & MAP2_HUMAN & 63 & 199,860 & $13(1)$ & $10(1)$ & 0.02 \\
\hline 21 & PP1RB_HUMAN & 63 & 14,229 & $1(1)$ & $1(1)$ & 0.24 \\
\hline 22 & UB2V2_HUMAN & 63 & 16,409 & $4(2)$ & $4(2)$ & 0.45 \\
\hline 23 & NFU1_HUMAN & 63 & 28,615 & $3(2)$ & $2(2)$ & 0.25 \\
\hline 24 & TPBG_HUMAN & 63 & 46,573 & $2(2)$ & $2(2)$ & 0.15 \\
\hline 25 & CR025_HUMAN & 62 & 43,526 & $4(1)$ & $4(1)$ & 0.08 \\
\hline 26 & 4EBP1_HUMAN & 61 & 12,686 & $2(2)$ & $2(2)$ & 0.61 \\
\hline 27 & AGO2_HUMAN & 61 & 98,400 & $7(1)$ & $6(1)$ & 0.03 \\
\hline 28 & I2BP2_HUMAN & 60 & 61,728 & $2(1)$ & $2(1)$ & 0.05 \\
\hline 29 & RABP2_HUMAN & 60 & 15,854 & $3(2)$ & $3(2)$ & 0.47 \\
\hline 30 & C1QBP_HUMAN & 59 & 31,742 & $1(1)$ & $1(1)$ & 0.1 \\
\hline 31 & YLPM1_HUMAN & 59 & 220,077 & $12(2)$ & $11(2)$ & 0.03 \\
\hline 32 & PSB9_HUMAN & 58 & 23,364 & $2(1)$ & $2(1)$ & 0.14 \\
\hline 33 & BASI_HUMAN & 58 & 42,573 & $2(2)$ & $2(2)$ & 0.16 \\
\hline 34 & COX5A_HUMAN & 58 & 16,923 & $2(1)$ & $2(1)$ & 0.2 \\
\hline 35 & MAVS_HUMAN & 58 & 57,063 & $1(1)$ & $1(1)$ & 0.06 \\
\hline 36 & BET1L_HUMAN & 57 & 12,437 & $3(1)$ & $3(1)$ & 0.28 \\
\hline 37 & ATIF1_HUMAN & 57 & 12,241 & $9(2)$ & $6(1)$ & 0.28 \\
\hline
\end{tabular}

Abbreviations: Score, protein score; Mass, molecular weight of matched protein; Matches, figures in brackets indicate the number of matched peptides $(P<0.05)$; Sequences, type of peptide segment sequences which matches the respective peptide $(P<0.05)$; emPAl, index of protein abundance

patients. Furthermore, the effects of HOTTIP on SCLC cell proliferation and cell cycle regulation indicated that HOTTIP could promote SCLC tumorigenesis. We also demonstrated that HOTTIP was involved in SCLC pathogenesis through ceRNA network "HOTTIP/miR574-5p/EZH1", then led to the occurrence and progression of SCLC. This study may provide a strategy and lead to the development of lncRNAs directed diagnostics and therapeutics against SCLC.

\section{Methods}

Human tissue specimens and cell culture

A total of 50 formalin-fixed, paraffin-embedded (FFPE) tissues were obtained from patients who had underwent bronchofiberscopy or biopsy for SCLC diagnosis during January 2008 to January 2015 and receiving care and follow-up at Shunde Hospital, Southern Medical University. The non-tumoral lung tissues in our study are all from the lung benign diseases including bronchiectasis and pulmonary bulla by thoracoscopic lobectomy. Informed consent was obtained from all patients and the study was approved by the Hospital's Protection of $\mathrm{Hu}$ man Subjects Committee.

H146, H446, H69, H69AR and 16-HBE cell lines were got from the American Type Culture Collection (ATCC, USA), cultured in RPMI 1640 medium containing 10\% or $20 \%$ fetal bovine serum in a humidified incubator at $37{ }^{\circ} \mathrm{C}$ with $5 \% \mathrm{CO}_{2}$ respectively. The H446AR cell line was obtained by culturing $\mathrm{H} 446$ cell line in gradually increasing doses of adriamycin (ADM) up to $0.8 \mu \mathrm{M}$ after a total of 14 months in our laboratory according to literature report [11]. The drug-resistant cells were maintained in drug-free medium for at least 2 weeks before any experiment. However, these drug resistant cell lines were also used for SCLC pathogenesis studies here.

According to the expression of HOTTIP in five cell lines above (Fig. 1c), we used H146/H446AR cell lines among which HOTTIP highly expressed to carry out loss-of-function experiments, while H446/H69 cell lines were used for gain-of-function experiments.

\section{Microarray analysis}

For lncRNA microarrays (Arraystar company, USA) and miRNA microarrays (LCsciences), differentially expressed genes were ordered by $P$-value with a raw expression level over 400 folds. The detailed experimental procedures were performed as previously described [23].

\section{Overexpression and RNA interfere}

The overexpression plasmid pcDNA3.1-HOTTIP was given as a present from Pro.Kevin Wang (Standford University School of Medicine). The pcDNA3.1-NC plasmid, siRNAs/shRNAs and miRNA mimics/inhibitors/antagomirs were purchased from GenePharma. The effective interference sequences were all selected by RTqPCR for the best gene silencing effect and then used for subsequent experiments. For stable transfection, 

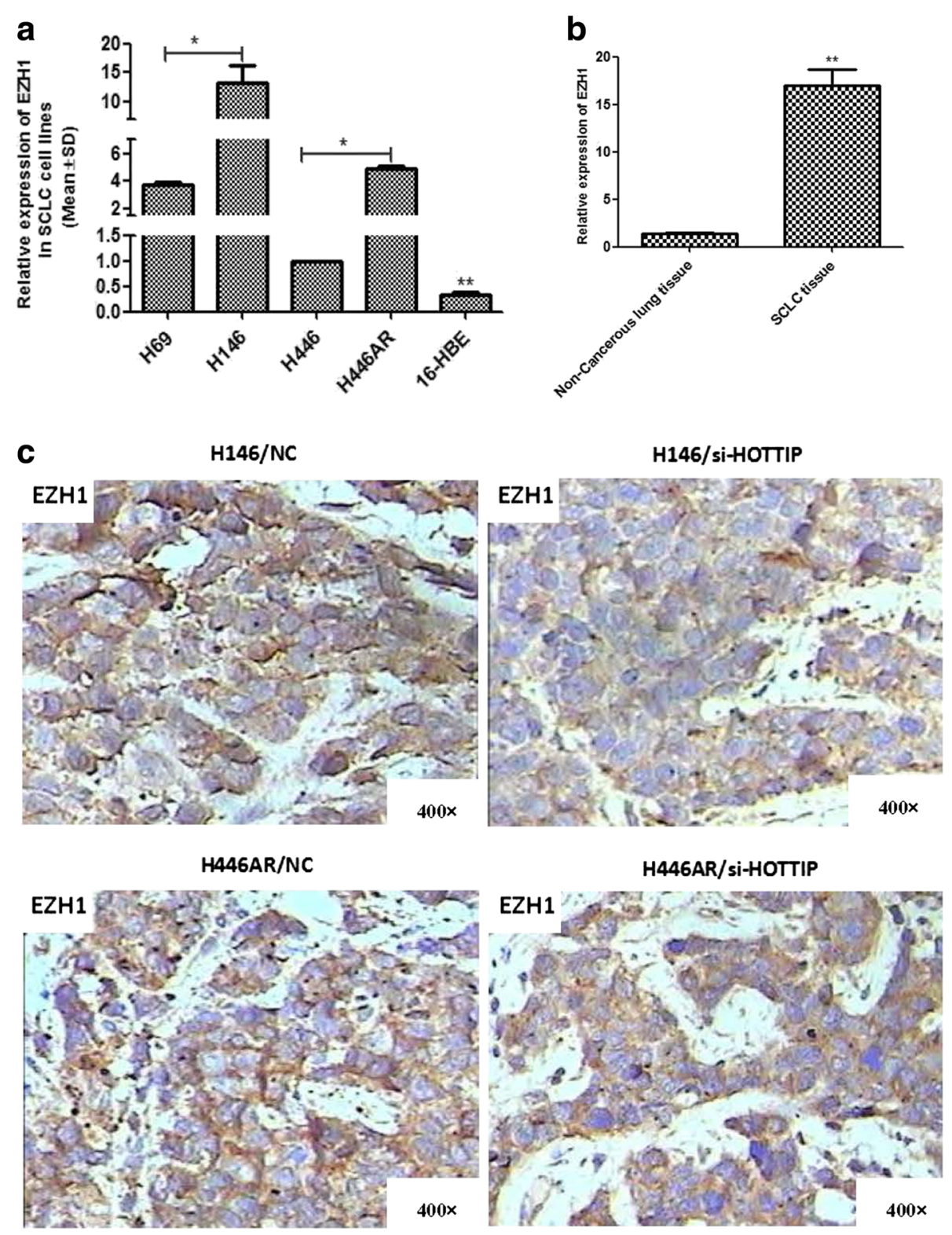

Fig. 6 HOTTIP may be involved in SCLC progression partly by regulating EZH1. a Differential expression of EZH1 in SCLC cell lines and 16-HBE cell line by RT-qPCR. $\mathbf{b}$ Differential expression of EZH1 in SCLC tissues and non-tumoral lung tissues by RT-qPCR. c HOTTIP may positively regulate expression of EZH1 protein in xerograft tumor tissues by immunohistochemistry technique. ${ }^{*}, P<0.05$

positive transfectants were selected with $400 \mu \mathrm{g} / \mathrm{ml}$ G418 (Calbiochem), while HOTTIP siRNAs were pakaged by lentivirus. The related siRNAs, shRNAs or miRNA mimics/inhibitors/antagomirs sequences were listed in Additional file 4.

\section{Reverse transcription quantitative PCR (RT-qPCR)}

RT-qPCR was used to detect expression levels of HOTTIP and other genes in SCLC cancer tissues and cells according to the manufacturer's instructions (TAKARA). GAPDH was used as the control. Related primers are listed in Additional file 4.

\section{Western blot and immunohistochemistry staining (IHC) analysis}

Western blot and immunohistochemistry staining (IHC) analysis were performed according to standard protocols as described previously $[8,13]$. All antibodies information is listed in Supplemental material.

\section{RNA pull-down assay}

Briefly, biotin-labeled RNAs were transcribed in vitro with the Biotin RNA Labeling Mix (Roche) and T7 RNA polymerase (Roche), treated with RNase-free DNase I (Roche), and purified with the RNeasy Mini Kit 

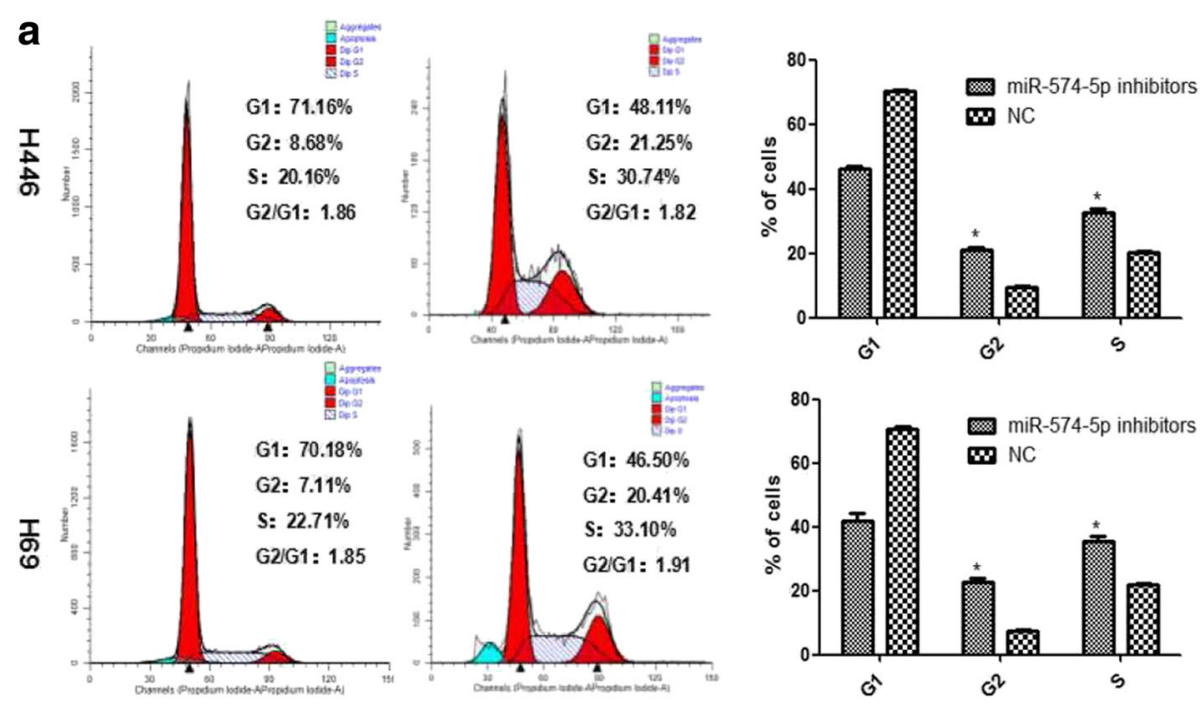

b

miR-574-5p inhibitors
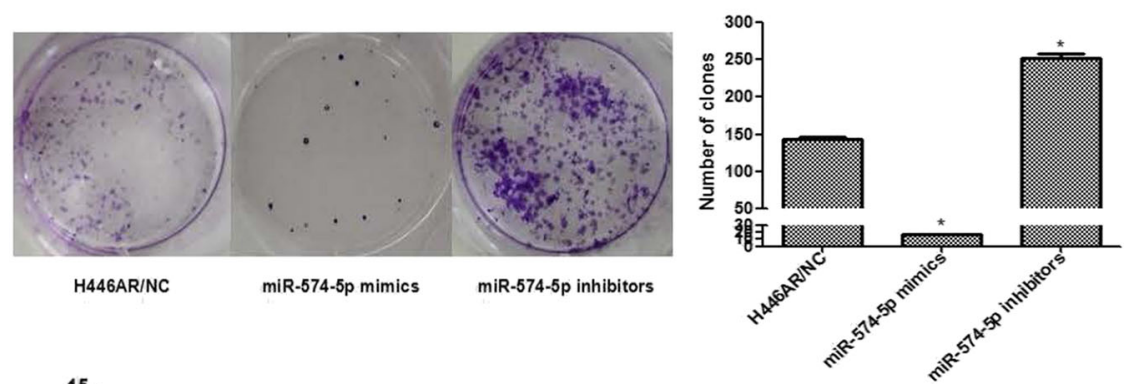

C
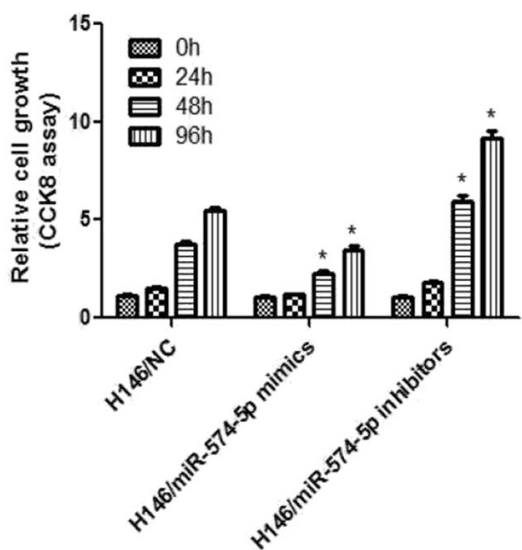

Fig. 7 miR-574-5p may be involved in SCLC progression. a Flow-cytometric analysis was used for cell cycle detection after miR-574-5p suppression in H446 and H69 cells. b Plate clone formation assay showed miR-574-5p may inhibit SCLC cell proliferation. c CCK8 assay showed miR-574-5p may inhibit SCLC cell proliferation. ${ }^{*}, P<0.05$

(Qiagen). The procedure was carried out according to the manufactures's instructions and standard protocols as described previously [24].

\section{Mass spectrometry}

HOTTIP and antisense strand protein bands acquired by RNA pull-down assay were excised and examined by mass spectrometry to detect the related protein combined directly with HOTTIP. The procedure was carried out according to standard protocols described previously [19].

RNA immunoprecipitation (RIP)

RIP assay is used to check whether miRNAs regulating their target genes trough RISC. The MS2bs-MS2bp- 
based RIP assay was carried out according to previous reports [25].

\section{In vitro proliferation assay}

Cell counting kit 8 (CCK8) experiment for in vitro proliferation assay were performed using the CCK8 Kit (Dojindo) according to the manufacturer's instructions as described previously [26].

For soft agar colony formation (for suspensioncultured H69 cell) and plate colony formation experiments, they were carried out according to standard protocols described previously [27].

\section{In vivo SCLC xenograft model in nude mice}

SCLC xenograft tumor formation experiment in nude mice was carried out according to the institutional guidelines of Guangdong Province and being approved by the Use Committee for Animal Care. Twenty-four $\mathrm{BALB} / \mathrm{c}$ nude mice (male, 5-6 weeks old, $18.0 \pm 0.5 \mathrm{~g}$ ) were got from the Guangdong Medical Animal Center, this experiment was carried out at the Animal Experimental Department of Sun Yat-sen University North District. They were randomly divided into the following groups ( $n=6$ mice per group): (a) H146/NC; (b) H146/ si-HOTTIP; (c) H446AR/NC; (d) H446AR/si-HOTTIP. H146 and H446AR cells with stable HOTTIP knockdown by lentivirus infection were injected into the flanks of nude mice at a concentration of $1 \times 10^{7}$ cells per $0.2 \mathrm{ml}$. The tumors were measured every 3 or 4 days, and tumor volume was calculated using the following formula: volume $=\left(\mathrm{L} \times \mathrm{W}^{2}\right) / 2$, among which $\mathrm{L}$ and $\mathrm{W}$ are the longest and shortest diameters, respectively. The mice were sacrificed when the average $\mathrm{L}$ of any group reached approximately $1 \mathrm{~cm}$.

\section{Flow cytometric analysis for cell cycle}

Cell cycle assay were performed after cells being fixed in $70 \%$ ethanol overnight at $4{ }^{\circ} \mathrm{C}$, and then were stained with propidium iodide. The detailed procedure was carried out according to standard protocols described previously [22].

\section{Luciferase reporter assay}

PSICHECK2.0 plasmid encoding a luciferase reporter gene was purchased from Promega. Recombinant plasmid of PSICHECK2.0-H-HOTTIP-3'-UTR, PSICHECK2.0-H-EZH13 '-UTR (wild type) or corresponding mutant type were constructed in GenePharma. SCLC cells $\left(2 \times 10^{5}\right.$ cells/well $)$ were spread in a 12-well plate and co-transfected with $40 \mathrm{nM}$ of either hsa-miR-574-5p or miRNA negative control of either recombinant plasmids or corresponding mutants, and $1 \mathrm{ng}$ of PSICHECK2.0 (Promega) by using Lipofectamine ${ }^{\text {Tu }} 2000$. The PSICHECK2.0 vector was used as an internal control to correct the differences in both transfection and harvest efficiency. Cells were collected $48 \mathrm{~h}$ after transfection and analyzed using the dual luciferase reporter assay system (Beyotime Biotechnology).

\section{Statistical analysis}

All experiments were run in triplicate. Data were represented as Mean \pm Standard Deviation (SD). All statistical analyses were carried out using SPSS 13.0 Statistics Software. $P<0.05$ was considered significant.

\section{Additional files}

Additional file 1: HOTTIP and miR-574-5p were screened out by microarray and RT-qPCR methods. (JPEG $275 \mathrm{~kb}$ )

Additional file 2: HOTTIP regulated the cell cycle of SCLC cells. (JPEG $353 \mathrm{~kb}$ )

Additional file 3: Cell location of HOTTIP and verification of their targeted regulatory relationships in cytoplasm and nucleus. (JPEG $107 \mathrm{~kb}$ )

Additional file 4: Legends of supplementary figures, primers, RNAi sequences, miRNA and antibodies information. (DOC $633 \mathrm{~kb}$ )

\section{Abbreviations}

ceRNA: Competing endogenous RNA; FFPE: Formalin-fixed, paraffinembedded; H3K27me3: Histone H3 lysine 27 trimethylation; HOTTIP: HOXA transcript at the distal tip; LncRNA: Long non-coding RNA; PRC2: Polycomb Repressive Complex 2; RIP: RNA binding protein immunoprecipitation; RT-qPCR: Reverse transcription quantitative PCR; SCLC: Small cell lung cancer

\section{Acknowledgements}

We highly appreciate and gratitude for the HOTTIP expression vector from professor Chang HY of Stanford University School of Medicine.

The flow cytometric analysis experiments were supported by the Guangdong Provincial Key Laboratory of Malignant Tumor Epigenetics and Gene Regulation, Sun Yat-Sen Memorial Hospital, Sun Yat-Sen University.

\section{Funding}

This work was supported by the National Natural Science Foundation of China (81372508), Clinical research initiative project of Southern Medical University (LC2016ZD029), and Guangdong Natural Science Foundation (Special fund for Scientific and Technological Development) (2016A030313822, 2017A030313644).

Availability of data and materials Not applicable.

\section{Authors' contributions}

GL and SY conceived and designed the experiments. SY, ZY and BY performed the experiments. WQ, BJ, LY and SY analyzed the data. SY, WQ and GL wrote the paper. The first three authors contribute equally to this paper. All authors read and approved the final manuscript.

\section{Ethics approval and consent to participate}

Under the protocol approved by the Institutional Review Board, informed consent was obtained from the patients or their guardians. The Ethical Committee of Shunde first people's hospital affiliated to Southern Medical University approved the tissue collection and studies with collected tumor tissues. All procedures involving animals were performed according to the guidelines of the Association for the Assessment and Accreditation of Laboratory Animal Care International.

\section{Consent for publication}

No conflict of interest exits in the submission of this manuscript, and manuscript is approved by all authors for publication. 


\section{Publisher's Note}

Springer Nature remains neutral with regard to jurisdictional claims in published maps and institutional affiliations.

\section{Author details}

'Department of Pathology, Zhujiang Hospital, Southern Medical University, Guangzhou 510282, China. ²Department of Pathology, Guangdong Medical University, Dongguan, China. ${ }^{3}$ Department of Pathology, Shunde Hospital, Southern Medical University, Guangdong, China. ${ }^{4}$ Department of Oncology, Sichuan Academy of Medical Sciences and Sichuan Provincial People's Hospital, Chengdu, China. ${ }^{5}$ Department of Organ transplantation, Zhujiang Hospital, Southern Medical University, Guangzhou 510282, China.

Received: 28 April 2017 Accepted: 2 October 2017

Published online: 17 October 2017

\section{References}

1. Schneider BJ, Kalemkerian GP. Personalized Therapy of Small Cell Lung Cancer. Adv Exp Med Biol. 2016;890:149-74.

2. Abazovic AM, Sisic I, Kovcin V, et al. Comparison of efficiency and toxicity of two chemotherapy protocols in treatment of advanced non-small cell lung cancer. Med Pregl. 2011;64:368-72.

3. Huarte M. The emerging role of IncRNAs in cancer. Nat Med. 2015;21:1253-61.

4. Gomes AQ, Nolasco S, Soares H. Non-coding RNAs: multi-tasking molecules in the cell. Int J Mol Sci. 2013;14:16010-39.

5. Simon MD, Pinter SF, Fang $R$, et al. High-resolution Xist binding maps reveal twostep spreading during X-chromosome inactivation. Nature. 2013;504:465-9.

6. Zhang J, Zhang $P$, Wang $L$, et al. Long non-coding RNA HOTAIR in carcinogenesis and metastasis. Acta Biochim Biophys Sin. 2014;46:1-5.

7. Zhang J, Zhang A, Wang Y, et al. New insights into the roles of ncRNA in the STAT3 pathway. Future Oncol. 2012;8:723-30.

8. Liu XH, Sun $M$, Nie FQ, et al. Lnc RNA HOTAIR functions as a competing endogenous RNA to regulate HER2 expression by sponging miR-331-3p in gastric cancer. Mol Cancer. 2014;13:92

9. Liang WC, WM F, Wong CW, et al. The IncRNA H19 promotes epithelial to mesenchymal transition by functioning as miRNA sponges in colorectal cancer. Oncotarget. 2015;6:22513-25.

10. Cai $B$, Song $X Q$, Cai JP, et al. HOTAIR: a cancer-related long non-coding RNA. Neoplasma. 2014;61:379-91.

11. Huang MD, Chen WM, Qi FZ, et al. Long non-coding RNA TUG1 is upregulated in hepatocellular carcinoma and promotes cell growth and apoptosis by epigenetically silencing of KLF2. Mol Cancer. 2015;14:165.

12. Richards EJ, Permuth-Wey J, Li Y, et al. A functional variant in HOXA11-AS, a novel long non-coding RNA, inhibits the oncogenic phenotype of epithelial ovarian cancer. Oncotarget. 2015;6:34745-57.

13. Li T, Mo X, Fu L, et al. Molecular mechanisms of long noncoding RNAs on gastric cancer. Oncotarget. 2016;7:8601-12.

14. Prensner JR, lyer MK, Balbin OA, et al. ranscriptome sequencing across a prostate cancer cohort identifies PCAT-1, an unannotated lincRNA implicated in disease progression. Nat Biotechnol. 2011;29(8):742-9.

15. Gupta RA, Shah N, Wang KC, et al. Long non-coding RNA HOTAIR reprograms chromatin state to promote cancer metastasis. Nature. 2010; 464(7291):1071-6

16. Wang KC, Yang YW, Liu B, et al. A long noncoding RNA maintains active chromatin to coordinate homeotic gene expression. Nature. 2011:472:120-4.

17. Zhao J, Ohsumi TK, Kung JT, et al. Genome-wide identification of polycomb-associated RNAs by RIP-seq. Mol Cell. 2010;40:939-53.

18. Gagnon KT, Li L, Chu Y, et al. RNAi factors are present and active in human cell nuclei. Cell Rep. 2014;6:211-21.

19. Wei Y, Li L, Wang $D$, et al. Importin 8 regulates the transport of mature microRNAs into the cell nucleus. J Biol Chem. 2014;289:10270-5.

20. Wang X, Li M, Wang Z, et al. Silencing of long noncoding RNA MALAT1 by miR-101 and miR-217 inhibits proliferation, migration, and invasion of esophageal squamous cell carcinoma cells. J Biol Chem. 2015;290:3925-35.

21. Leucci E, Patella F, Waage J, et al. microRNA-9 targets the long non-coding RNA MALAT1 for degradation in the nucleus. Sci Rep. 2013:3:2535.

22. Han Y, Liu Y, Zhang H, et al. Hsa-miR-125b suppresses bladder cancer development by down-regulating oncogene SIRT7 and oncogenic long non-coding RNA MALAT1. FEBS Lett. 2013;587:3875-82.
23. Liu YW, Sun M, Xia R, et al. LincHOTAIR epigenetically silences miR34a by binding to PRC2 to promote the epithelial-to-mesenchymal transition in human gastric cancer. Cell Death Dis. 2015;6:e1802.

24. Lu H, He $Y$, Lin $L$, et al. Long non-coding RNA MALAT1 modulates radiosensitivity of HR-HPV+ cervical cancer via sponging miR-145. Tumour Biol. 2016;37:1683-91.17.

25. Miao L, Huang Z, Zengli Z, et al. Loss of long noncoding RNA FOXF1-AS1 regulates epithelial-mesenchymal transition, stemness and metastasis of non-small cell lung cancer cells. Oncotarget 2016; e-pub ahead of print 26 Aug 2016; doi: 10.18632/oncotarget.11630.

26. Sun Y, Bai $Y$, Zhang $F$, et al. miR-126 inhibits non-small cell lung cancer cells proliferation by targeting EGFL7. Biochem Biophys Res Commun. 2010;391:1483-9.

27. Niu Y, Ma F, Huang W, et al. Long non-coding RNA TUG1 is involved in cell growth and chemoresistance of small cell lung cancer by regulating LIMK2b via EZH2. Mol Cancer. 2017;16(1):5.

\section{Submit your next manuscript to BioMed Central and we will help you at every step:}

- We accept pre-submission inquiries

- Our selector tool helps you to find the most relevant journal

- We provide round the clock customer support

- Convenient online submission

- Thorough peer review

- Inclusion in PubMed and all major indexing services

- Maximum visibility for your research

Submit your manuscript at www.biomedcentral.com/submit
Biomed Central 